\title{
Follow-Up Form Outcome Measure of Success Not Applicable
}

National Cancer Institute

\section{Source}

National Cancer Institute. Follow-Up Form Outcome Measure of Success Not Applicable. NCl Thesaurus. Code C160284.

The outcome after completion of this form is not applicable. 